\title{
PHOTOGRAPHY OF LENS OPACITIES BY TRANS-SCLERAL ILLUMINATION*
}

BY

\author{
A. J. OGG \\ Salisbury
}

FinCHAM (1955) discussed the value of photographically recording the progress of cataract and described a method whereby lens opacities were photographed by the light reflected from the fundus by trans-pupillary trans-illumination. A slit lamp was used, in which the axis of illumination was coincident with the line of observation; the mirror of the illuminating system was replaced by a thin glass plate and the microscope by a single lens reflex camera. With this method, lens opacities were seen as dark areas against the luminous background of the fundus, and contrast was increased with a dark orange filter in the illuminating or camera system. Previously, Douvas and Allen (1950) had photographed lens opacities with the Nordenson retinal camera; in their photographs opacities also showed as dark areas against the retinal reflex.

In the method now to be described the cataract is focally illuminated by light introduced into the eye through the lower lid and sclera; reflected light from the fundus is kept to a minimum, and the lens opacity is seen as a white area against the dark fundus background.

\section{Apparatus}

The trans-illuminator and camera systems are illustrated in Fig. 1 (opposite). The trans-illuminator consists of a lamp-house made from a cylindrical tin can, in which is mounted a Philips PF5 flash-bulb. This particular bulb has a maximum light flux of 1.4 millions of lumens, with a flash duration of $1 / 50$ th part of a second. Attached to the lamp-house is a cardboard cone which terminates in a perspex rod, on to which a condensing lens focuses light from the flash-bulb. The transilluminator is coated with matt black paint, except for its apex: it is $12 \mathrm{~cm}$. in length, light, and easy to handle.

The camera is of the single-lens reflex type (a Reflex Korelle) with a $3^{\prime \prime}$ focal length lens and a maximum marked aperture of F 3.5. The film used is Kodak Royal-X Pan. which is one of the fastest films readily available at the present time. The shutter is synchronized through a battery and capacitor to the flash-bulb in the trans-illuminator. The camera is mounted on the geometric microscope stand of a disused Zeiss slit lamp (Hansell, 1957) and placed on a slit-lamp table. (The type of slit lamp is not important, but the Hamblin "Universal" proved ideal for this purpose).

\footnotetext{
* Received for publication July 2, 1959.
} 


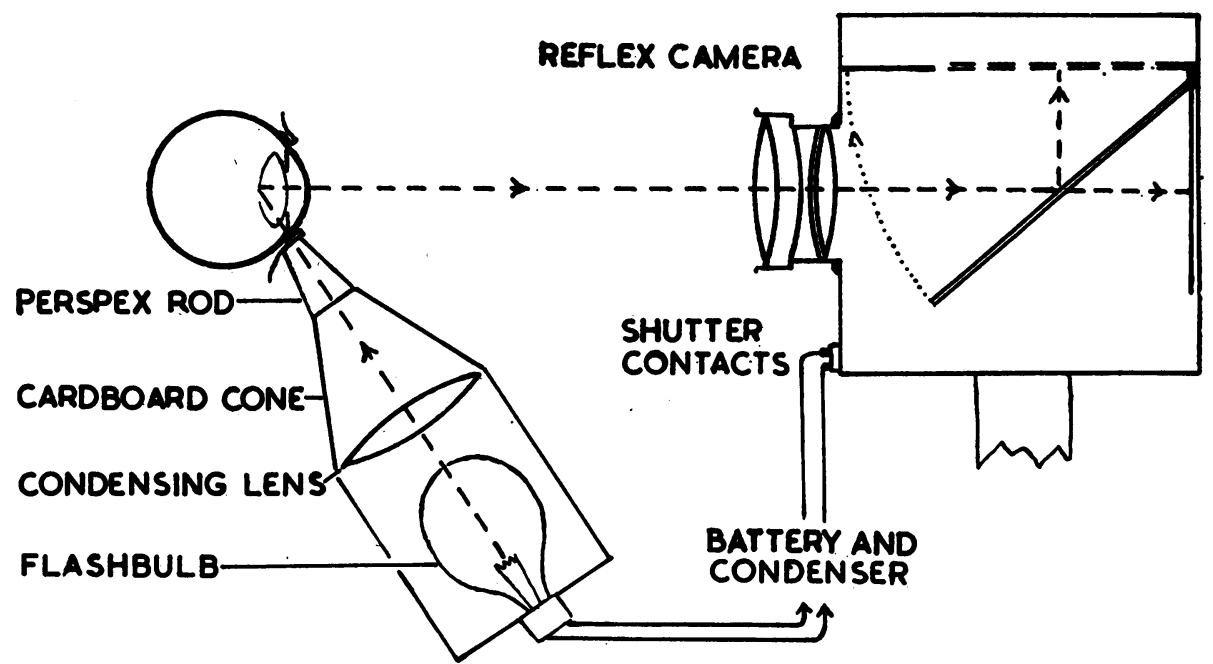

Fig. 1.-Diagram to show construction of trans-illuminator connected to flash contacts of Reflex camera.

\section{Method}

The patient's cataractous eye is dilated with homatropine and cocaine and his head is positioned on the slit-lamp head-rest. The image of the cataract, illuminated by the slit-lamp illuminating system, is focused on the ground-glass screen of the camera. The apex of the trans-illuminator is now placed against the skin in the centre of the patient's lower lid and gently pressed in an upward and inward direction; the light from the slit lamp is turned off and the exposure made. An assistant can help considerably by lifting the patient's upper lid and turning off the light of the slit lamp a moment before the exposure.

As with Fincham's technique, the depth of field is small, and if a photographic record is required of lens opacities occupying different depths in the lens, then each successive layer must be photographed in turn. Fig. 2 shows a photograph of senile nuclear and cortical cataracts which are not in the same plane. The camera was focused on an intermediate position with the result that neither is sharply defined. In the photograph the outline of the ciliary body can be seen.

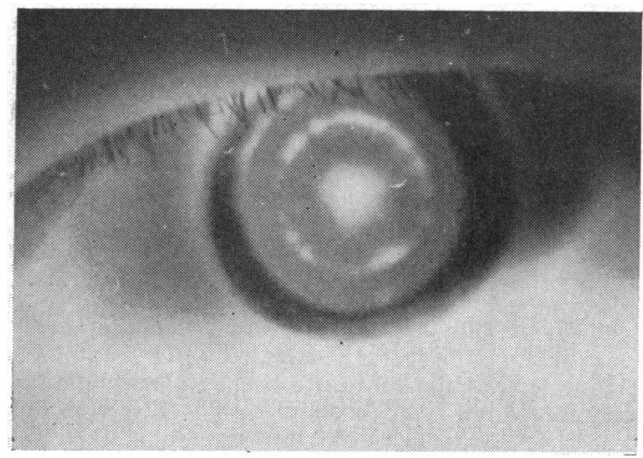

FIG. 2.-Senile cortical and nuclear opacities; the outline of the ciliary body is also shown. 

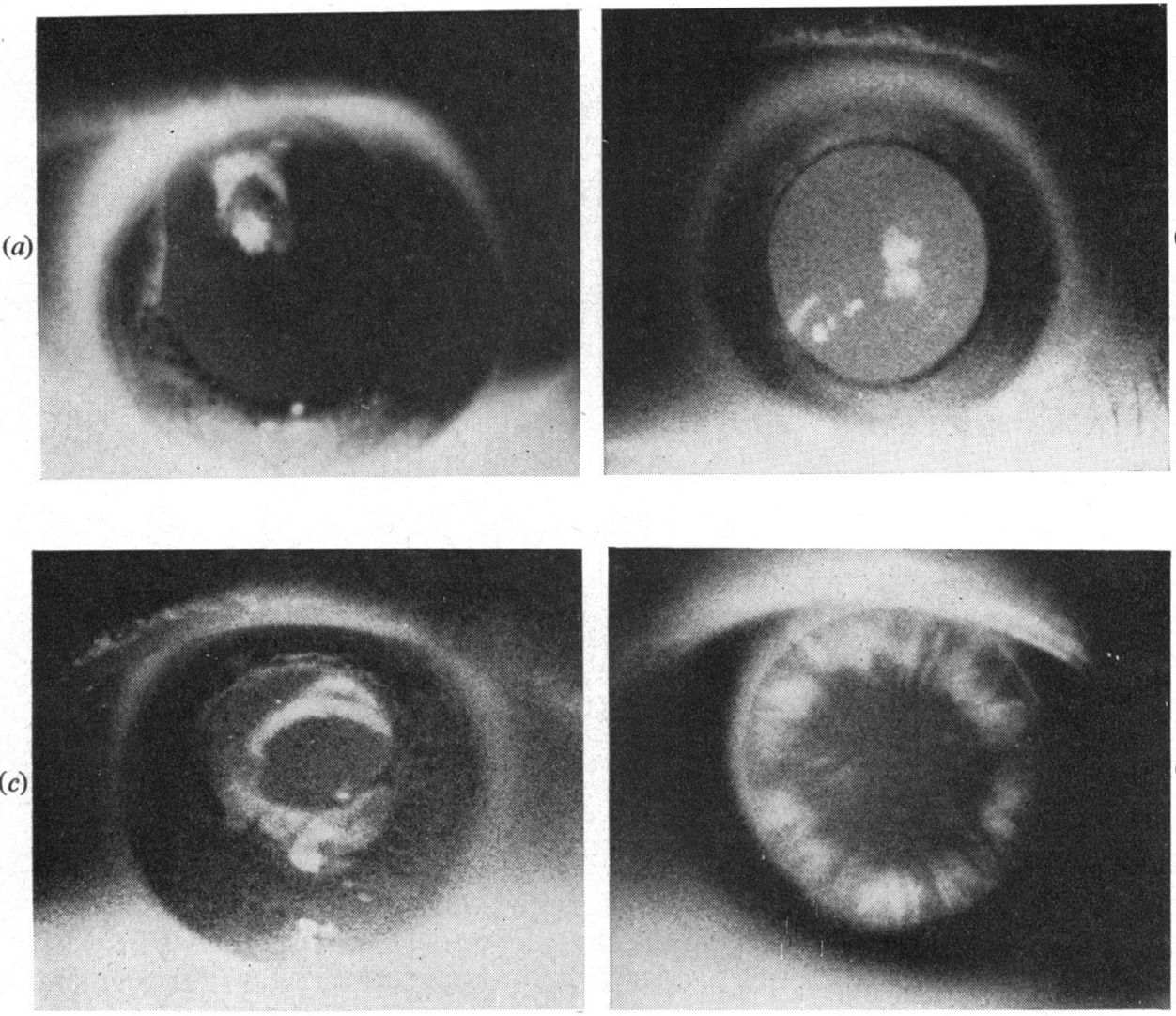

保

(d)
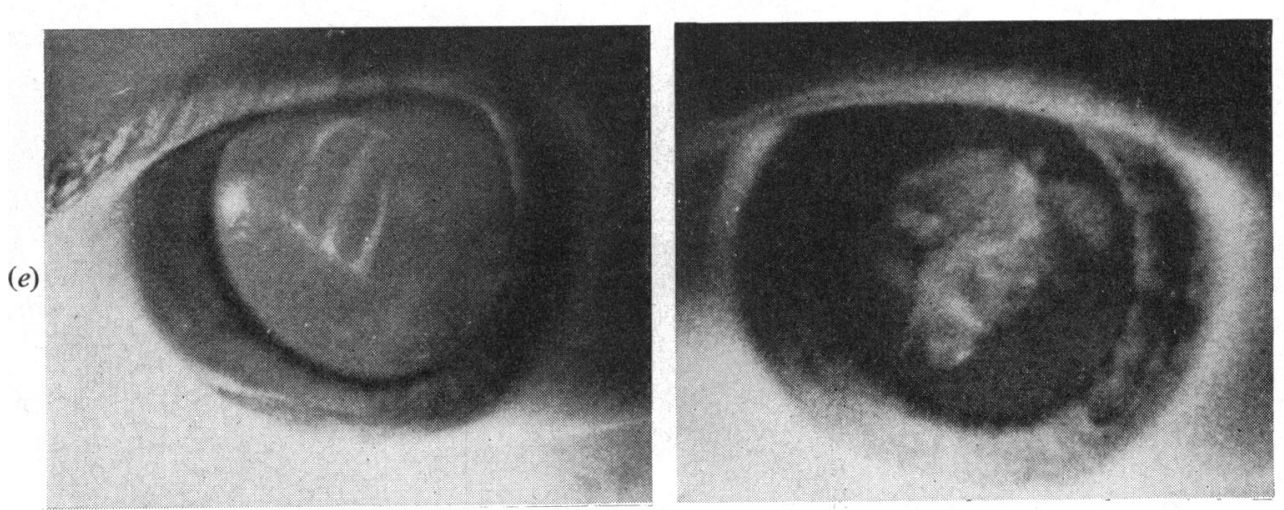

FIG. 3(a)-Broad iridectomy and localized cataract following an intra-ocular foreign body. (b) Localized lens opacities following a non-perforating injury. (c) Absorption of traumatic cataract resulting from a perforating injury, showing capsule and soft lens matter remnants.

$(d)$ Senile cortical opacities. (e) Congenital cataract $24 \mathrm{hrs}$ after discission. $(f)$ The same eye as $3(e) 8$ days after discission. 
The length of the exposure is that of the flash-1/50th part of a second-hence ocular movements of small degree are of no consequence, the patient does not experience any discomfort, and there is no after-image. In the rare eventuality of a flash-bulb explosion, the eye is well protected by the structure of the trans-illuminator. In practice the method has proved quick and easy to carry out, and gives consistent results. The majority of photographs are completely free from corneal reflex but great care is necessary to reduce the general room illumination to a minimum, since the film is extremely sensitive. In some cases the application of the transilluminator will result in slight eversion of the lower lid, and scattered light from the tarsal conjunctiva will produce small reflexes in the lower part of the cornea.

Fig. 3 shows various lens opacities photographed by the method.

I should like to thank Mr. R. Conroy for his help in photographic processing, and the Wessex Regional Hospital Board for a grant to carry out this work.

\section{REFERENCES}

Douvas, N., and Allen, L. (1950). Amer. J. Ophthal., 33, 291.

FinCHAM, E. F. (1955). Brit. J. Ophthal., 39, 85.

HANSELL, P. (1957). "A System of Ophthalmic Illustration", p. 28 (Amer. Lect. Ser. No. 289). Thomas, Springfield, Ill. 